6-1-2003

\title{
Systemic sclerosis: current views of its pathogenesis.
}

Chris T. Derk

Thomas Jefferson University

Sergio A. Jimenez

Thomas Jefferson University

Follow this and additional works at: https://jdc.jefferson.edu/medfp

Part of the Rheumatology Commons

Let us know how access to this document benefits you

\section{Recommended Citation}

Derk, Chris T. and Jimenez, Sergio A., "Systemic sclerosis: current views of its pathogenesis." (2003). Department of Medicine Faculty Papers. Paper 207.

https://jdc.jefferson.edu/medfp/207

This Article is brought to you for free and open access by the Jefferson Digital Commons. The Jefferson Digital Commons is a service of Thomas Jefferson University's Center for Teaching and Learning (CTL). The Commons is a showcase for Jefferson books and journals, peer-reviewed scholarly publications, unique historical collections from the University archives, and teaching tools. The Jefferson Digital Commons allows researchers and interested readers anywhere in the world to learn about and keep up to date with Jefferson scholarship. This article has been accepted for inclusion in Department of Medicine Faculty Papers by an authorized administrator of the Jefferson Digital Commons. For more information, please contact: JeffersonDigitalCommons@jefferson.edu. 
Derk CT and Jimenez SA. Systemic Sclerosis: Current views of its pathogenesis. Autoimmunity Reviews 2:181-191, 2003.

\title{
SYSTEMIC SCLEROSIS: CURRENT VIEWS OF ITS PATHOGENESIS
}

\author{
Chris T. Derk and Sergio A. Jimenez \\ Department of Medicine, Division of Rheumatology \\ Thomas Jefferson University \\ Philadelphia, PA 19107
}

Address all correspondence to:

Sergio A. Jimenez, M.D.

Thomas Jefferson University

Division of Rheumatology

233 S. $10^{\text {th }}$ Street, Room 509 BLSB

Philadelphia, PA 19107-5541

Phone: 215-503-5042

Phone: 215-923-4649

E-mail: Sergio.Jimenez@mail.tju.edu 


\begin{abstract}
Systemic Sclerosis (SSc) is an autoimmune disorder of unknown etiology characterized by severe and often progressive cutaneous and visceral fibrosis, pronounced alterations in the microvasculature, and numerous cellular and humoral immune abnormalities. Clinically, SSc is very heterogeneous encompassing a spectrum ranging from mild limited forms of skin sclerosis with minimal internal organ involvement to severe skin and multiple internal organ fibrosis. Mortality and morbidity in SSc are very high and are directly related to the extent of the fibrotic and microvascular alterations. A better understanding of the pathogenesis of this incurable disorder will help to better target and design effective therapy in the future.
\end{abstract}

Keywords: Systemic sclerosis, scleroderma, fibrosis, autoantibodies, transforming growth factor $\beta$, collagen genes, transcription factors.

- Autoimmune disease of unknown etiology.

- Severe and often progressive cutaneous and visceral organ fibrosis.

- Numerous humoral and cellular immune abnormalities including production of specific autoantibodies, cytokine and growth factor dysregulation and mononuclear cell infiltration of affected tissues.

- Transforming growth factor $\beta$ and its regulatory pathways including the Smad proteins appear to be intimately involved in SSc pathogenesis.

- Abnormal regulation of expression of various collagen genes and of the transcriptional factors involved.

- Fibroproliferative vascular alterations and thrombosis responsible for the most serious clinical events such as renal crisis and pulmonary hypertension. 


\section{Introduction.}

Systemic Sclerosis (SSc) is an autoimmune inflammatory disorder of unknown etiology characterized by severe and often progressive cutaneous and visceral fibrosis, pronounced alterations in the microvasculature and frequent cellular and humoral immunity abnormalities as patients with SSc almost universally harbor numerous autoantibodies, some which are diseasespecific. Clinically, SSc is heterogeneous ranging from mild limited skin sclerosis (sclerodactily or acrosclerosis) with minimal organ involvement (limited SSc) to diffuse skin involvement and severe fibrosis of multiple internal organs (diffuse SSc), and occasionally a fulminant course with rapid development of vital organ failure and a lethal outcome (fulminant SSc). Morbidity and mortality in SSc are very high and are related to the extent of the fibrotic and microvascular alterations. A better understanding of the pathogenesis of this incurable disorder will help to better target and design effective therapy in the future.

Although the exact mechanisms involved in the pathogenesis of SSc are not well understood, there are three features responsible for the clinical and pathologic manifestations of the disease: (1) excessive deposition of collagen and other connective tissue macromolecules in skin and internal organs; (2) vascular lesions of small arteries; and (3) alterations of humoral and cellular immunity.

At present, it is not clear which of the three components of SSc pathogenesis is of primary importance or how they interrelate to cause the progressive fibrotic process. However, there has been a remarkable progress in the understanding of numerous basic mechanisms, which have shed light on the complex pathogenesis of the disease. 


\section{Are infectious agents involved in SSc pathogenesis?}

The etiology of SSc is not known, however, it is currently accepted that the disease results from complex interactions between one or more environmental factors and a genetic predisposition in the host which eventually result in the development of severe, generalized, and often progressive tissue fibrosis .

It has been postulated that infectious agents may be the causative agents of autoimmune disorders including SSc and retroviruses and human cytomegalovirus (HCMV) among others, have been considered putative etiologic agents. This hypothesis is based on observations indicating that production of specific autoantibodies in SSc may be due to an antigen driven response triggered by "molecular mimicry" between self-antigens sharing structural similarities to a foreign protein of viral or bacterial origin. Thus, the autoantibodies may represent footprints of the elusive etiologic agent. In support of this hypothesis it was shown that sequence homologies exist between the $\mathrm{p} 30^{\mathrm{gag}}$ retroviral proteins of various feline and murine viruses and topoisomerase I, the marker SSc antigen recognized by anti-Scl-70 antibodies (1).

Furthermore, antibodies to certain retroviral proteins have been found in sera from patients with SSc (2). Despite these observations a more direct evidence of retroviral involvement in the etiology or pathogenesis of SSc is needed. Another putative etiologic agent for SSc is HCMV. The possible involvement of HCMV is supported by the observations of higher prevalence in patients with SSc of IgG anti-HCMV antibodies capable of binding the HCMV late protein UL94 and inducing apoptosis in human endothelial cells (3), an increased prevalence of IgA HCMV in patients positive for Scl-70 autoantibodies, the development of severe fibro-proliferative vascular changes in certain cases of HCMV infections, and the occurrence of autoantibodies recognizing the U1 snRNP primarily directed against a $70 \mathrm{kD}$ 
protein in patients with HCMV infections (4). As is the case for retroviruses, there is no evidence to conclusively link HCMV infections with the development of SSc or with its clinical manifestations.

\section{Contribution of genetic factors.}

The contribution of genetic factors to the development and expression of SSc is strongly supported by: (1) the observation of familial clustering of the disease; (2) the high frequency of occurrence of other autoimmune disorders and autoantibody positivity in SSc family members;

(3) differences in SSc prevalence and clinical manifestations among different ethnic groups; and (4) the increased prevalence of certain human leukocyte antigen (HLA) and major histocompatibility complex (MHC) alleles among different ethnic groups and among patients with different types of disease or different patterns of autoantibodies (5). Although the concordance of SSc among identical twins is only 5.9\%, suggesting that the heritability component is rather low for SSc, this frequency is still about 300 times higher than that expected by chance alone. Furthermore, only a small group of twins has been studied (34 pairs) rendering it difficult to draw definitive conclusions. Other evidence for the contribution of genetic factors to the development of SSc has been gathered from the study of the frequency of occurrence of SSc in the Choctaw American Indians from Oklahoma in whom the prevalence of SSc is 469 cases/million population in contrast with that of the general prevalence of SSc in the United States of 242 to 286 cases/million population (6). The remarkably higher prevalence of SSc in the Choctaw appears to be associated with differences in MHC and HLA allele expression when comparing different ethnic groups. In the Choctaws, the HLA haplotypes found to be related with disease expression are DRB $1 * 1602$, DQA $1 * 0501$, DQB $1 * 0301$, whereas, in Caucasian populations from the United States and from Europe they are DRB1*1101, DRB1*1104, 
DQA1*1501, DQB1*0301, DRB1*0301, DQA1*0501, DQB1*0201. Certain patterns of disease expression also appear to be different among ethnic groups. For example, African American patients with SSc are more likely to be positive for anti-topoisomerase-1 antibodies, have worse disease manifestations with more pronounced systemic involvement and a higher frequency of pulmonary fibrosis. On the contrary, anti-centromere antibodies are more commonly seen in Caucasian patients who display more limited disease with less systemic manifestations $(5,6)$. In addition to providing a receptive environment for the development of SSc, genetic influences may also be involved in the phenotypic expression of the disease, thus, explaining the remarkable variability and the wide expression of clinical manifestations. In the case of SSc, these studies have been particularly focused on the potential influence of various genetic polymorphisms on the severity and progression of the fibrotic process by promoting increased collagen gene expression. In one study it was found that the presence of certain dinucleotide repeats in the upstream region of COL1A2 in patients with SSc resulted in its increased expression (7). Another study has shown that two different single nucleotide polymorphisms in the gene for transforming growth factor $\beta$ (TGF $\beta 1$ ), the potent profibrotic cytokine secreted from activated T-lymphocytes, are present in higher frequency in patients with SSc than in normal individuals (8). Also, a study of Japanese and Choctaw Indians with SSc found that a single nucleotide polymorphism in the non-coding region of the fibrillin-1 gene at chromosome $15 \mathrm{q}$ was strongly related to the development of SSc in these patients (9).

Although collectively these studies suggest an important contribution of genetic factors in the pathogenesis of SSc and, in particular, in the expression of specific SSc clinical subsets, at present, it appears more likely that genetic factors may provide a permissive environment that 
allows either the initiation of the disease process or its progression and development of clinical manifestations.

\section{Microchimerism: Does it play a role in SSc pathogenesis?}

A novel hypothesis suggesting that allogenic fetal and maternal cells which cross the placenta during pregnancy may be involved in the pathogenesis of SSc has recently been proposed. Fetal or maternal cells persist in the maternal or offspring blood and tissues likely as a result of HLA II (DRB1) compatibility between the mother and the fetus (10). It has been postulated that these engrafted fetal cells become activated by an environmental trigger and subsequently mount a graft-versus-host reaction towards the mother or offspring, which may result in the clinical symptoms of SSc. The identification of Y-chromosome sequences in the DNA obtained from skin biopsy specimens from female SSc patients who had previously given birth to male offspring provides strong support for this hypothesis (11). Also, the recent demonstration of microchimerism of maternal origin in blood and tissues of the offspring might explain the occurrence of SSc in nulliparous women and in men. There is substantial controversy regarding this hypothesis since several recent studies have shown that fetal Y chromosome DNA is present in normal controls, although other studies have indicated that it may be the quantity and not the mere presence of fetal cells that may be the crucial contributory factor in the pathogenesis of SSc $(12,13)$. Thus the intriguing and provocative hypothesis of microchimerism in the pathogenesis of SSc still remains controversial.

\section{Humoral immune system alterations.}

The presence of specific autoantibodies is one of the most common manifestations of SSc and greater than $90 \%$ of SSc patients have antinuclear antibodies in their serum. Numerous autoantibodies have been described in SSc patients (Table 1). Some of these are extremely 
specific for SSc, whereas others are associated with different clinical manifestations of the disease.

Anti-Scl-70 antibodies were initially described to recognize a 70-kD nuclear protein (14). Subsequently, it was shown that these antibodies react with a $110-\mathrm{kD}$ protein which has been identified as DNA topoisomerase I (15). These antibodies are almost exclusively present in sera from patients with the diffuse form of SSc. About 30-40\% of patients with diffuse SSc harbor these autoantibodies with a higher prevalence seen in African American patients.

Anti-centromere antibodies recognize several protein components of the tri-laminar kinetochore. The most common anticentromere antibodies recognize three different antigens: a $17 \mathrm{kD}$ (CENP-A), an $80 \mathrm{kD}$ (CENP-B) and a $140 \mathrm{kD}$ (CENP-C) centromere protein. These antibodies are usually present in patients with the limited form of SSc and are seen in 80 to $96 \%$ of these patients. In contrast to anti-Scl-70 antibodies, anti-centromere antibodies are only found in about $10 \%$ of patients with diffuse SSc. These two autoantibodies are mutually exclusive, coexisting in the same patient only in rare instances.

Other autoantibodies less commonly seen in SSc patients are anti-RNA polymerases I and III antibodies in patients with rapidly progressive disease and severe internal organ involvement, anti-fibrillarin antibodies directed against a $34 \mathrm{kD}$ nucleolar protein and commonly found in diffuse SSc, and anti-PM-Scl antibodies directed against eleven different nucleolar and nuclear proteins ranging in size from $20 \mathrm{kD}$ to $11 \mathrm{kD}$ which are usually related to a polymyositis SSc overlap syndrome. Although autoantibodies in SSc are very common, it is generally accepted that they are not directly involved in the clinical manifestations of the disease and their titers do not correlate with disease activity or clinical severity. 


\section{Cellular immune system and cytokine alterations.}

The presence of mononuclear cell infiltrates in affected skin and visceral organs from SSc patients has long been recognized. Early in the presentation of SSc, biopsies from affected skin show prominent macrophage and T-cell lymphocytic infiltrates (16). The cells in these early infiltrates are CD14+ and express Class II MHC, suggesting that they are activated. Prior activation of peripheral blood $\mathrm{T}$ cells in patients with SSc is also evident by the increased expression of high affinity IL-2R on the T-cell membranes and the observation that sera from SSc patients contain a three-fold higher level of serum IL-2. Subsequently, the majority of tissue-bound T-cell lymphocytes is CD4+ (helper T-cells) expressing the activation marker Class II MHC antigen DR. While this is true in most cases, a few studies have shown an increased prevalence of CD8+ cells in lymphocytic infiltrates from the skin and lungs. Most of these cells express $\alpha / \beta$ receptors rather than $\gamma / \delta$ receptors although $\gamma / \delta$ receptor bearing T-cells appear to be predominant in bronchial alveolar lavage fluids of patients with SSc interstitial lung disease (17). Further expansion of T-cells within the affected tissues appears to be oligoclonal as shown recently in studies of T-cell receptor transcripts in SSc skin (18). The expanded T-cell populations in affected SSc tissues are believed to release cytokines, which initiate and/or perpetuate the fibrotic process as well as the endothelial and vascular alterations. Indeed, clones of T-cells established from infiltrating lymphocytes isolated from affected SSc skin produce cytokines capable of modulating fibroblast proliferation and collagen production, as well as, various endothelial cell functions (19).

There are numerous cytokines which have been shown in in vitro studies to exert potent effects on the production and/or degradation of collagens (20). However, it is very likely that the ultimate effects of these cytokines on fibroblast biosynthetic activities depend on their 
concentration in the pericellular environment and on their relative proportions among a mixture of a large number of other cytokines which often have opposing effects on the target cells.

\section{The TGF $\beta$ signaling pathway: A key component of pathologic tissue fibrosis.}

Since the discovery of the potent profibrotic and immunomodulatory activities of TGF $\beta$, this growth factor has been considered one of the most likely molecules involved in the pathogenesis of SSc (21) and other fibroproliferative diseases (22), and a plethora of publications have described studies focused on this subject. Three functionally and structurally similar isoforms of TGF $\beta$ exist in humans and they play important roles in embryonic development, immune responses, and regulation of tissue repair following injury (23). One of the most important effects of TGF $\beta$ is the stimulation of ECM synthesis evidenced by a remarkable increase in the production of numerous matrix molecules. TGF $\beta$ also decreases the synthesis of collagen-degrading metalloproteinases and stimulates the production of protease inhibitors such as tissue inhibitors of metalloproteinases-1 (TIMP-1).

Small amounts of TGF $\beta$ appear to sensitize fibroblasts and maintain them in a persistently activated state involving an autocrine mechanism which causes further production of TGF $\beta$. Activated monocytes from SSc patients secrete TGF $\beta$ and the upregulation of this cytokine/growth factor appears to play a crucial role in the development of fibrosis in patients with SSc. It also appears that SSc fibroblasts express increased numbers of TGF $\beta$ receptors which might account for the increased TGF $\beta$-induced signaling and the resulting increased collagen production in these cells. TGF $\beta$ is synthesized as a 390-412 amino acid pre-pro-TGF $\beta$ molecule which then undergoes glycosylation to form a pro-TGF $\beta$ monomer. This monomer is then cleaved by endopeptidases to yield a $12.5 \mathrm{kDa}$ monomer while the cleaved fragment dimerizes to form a $75 \mathrm{kDa}$ latency binding peptide which assists in the folding of a $25 \mathrm{kDa}$ 
dimer resulting from the dimerization of the $12.5 \mathrm{kDa}$ monomers. A $135 \mathrm{kDa}$ latency binding peptide bearing mannose-rich carbohydrate then attaches to the $75 \mathrm{kDa}$ latency binding peptide to form the latent TGF $\beta$ complex (LT $\beta C$ ) which is secreted by the cell. Outside the cell LT $\beta C$ binds to mannose-6-phosphate receptors on cell membranes or to the extracellular matrix where activated cells such as macrophages release serine proteases which cleave the LT $\beta$ C and release active TGF $\beta$ (23). The intricate mechanisms involved in the transduction of TGF $\beta$ effects from the cell surface to the responsive genes have been recently elucidated $(24,25)$. BioactiveTGF $\beta$ binds to the cell surface TGF $\beta$ II receptor (T $\beta$ RII) in target cells to form a receptor complex which becomes activated and trans-phosphorylates, the T $\beta$ RI receptor causing its activation. Signaling from the phosphorylated TGF $\beta$ I receptor to the nucleus then occurs through the Smad family of proteins. Smad2 and Smad3 bind to the activated TGF $\beta$ receptor complex and they also become phosphorylated. Phosphorylation allows these proteins to form a complex with Smad4 which is a cytoplasmic protein involved in the translocation of the complex into the nucleus. Smad7 is an inhibitory Smad which can bind to the TGF $\beta$ receptor complex and prevent Smad2 or Smad3 phosphorylation. Once in the nucleus, Smad2/Smad4 or Smad3/Smad4 complexes bind directly to specific DNA binding sites in the promoter regions of target genes and activate their expression. The Smad3 complex binds to DNA sites in the promoter region of responsive genes with the help of intranuclear proteins which act as transcriptional partners. In contrast, Smad2 complexes do not bind to DNA promoter sites but exert their effect through other transcription factors or co-activator proteins. A diagrammatic representation of the TGF $\beta /$ SMAD pathway is shown in Figure 1. The potential involvement of the Smad proteins (26) and, in particular, of Smad7 in the pathogenesis of SSc has been 
suggested by a recent study which described substantially reduced levels of Smad7 in SSc fibroblasts and skin (27).

CTGF is another growth factor that appears also to play a crucial role in tissue fibrosis (28). In addition to a potent profibrotic effect, CTGF also participates in angiogenesis, axial development of the musculoskeletal system, structural organization of connective tissue, and embryo implantation. TGF $\beta$ stimulates CTGF synthesis in fibroblasts, vascular smooth muscle cells and endothelial cells. The CTGF produced by these cells in response to TGF $\beta$ stimulation in turn stimulates the synthesis of such ECM components as type I collagen and fibronectin in dermal and lung fibroblasts and very likely in endothelial cells. CTGF also appears to have an autocrine function stimulating its own production and, thus, maintaining a continuous or prolonged cycle of excessive scarring and fibrosis. Although the role of CTGF in the pathogenesis of SSc has not been completely elucidated, it has been postulated that it may, under certain conditions, represent a downstream mediator of TGF $\beta$ effects. Indeed, some studies have shown that CTGF expression is markedly increased in affected SSc tissues including skin and lung parenchyma.

Most recent studies on TGF $\beta$ regulation of fibroblast ECM production have focused on Smad signaling, however, it has been postulated that non-Smad pathways may be involved in TGF $\beta$ signaling. Certain intracellular enzymes have been identified to possibly play a role in TGF $\beta$ signaling including protein kinase $\mathrm{C}-\delta(\mathrm{PKC}-\delta)$, phosphatidylcholine-specific phospholipase C (PLC), geranylgeranyl transferase I, stress-activated protein kinase p38, and TGF $\beta$-activated kinase (TAK). Selective or specific inhibition of enzymes involved in nonSmad pathways of TGF $\beta$ regulation resulted in down-regulation of collagen gene expression in both normal and SSc fibroblasts. GGTI-298, a geranylgeranyl transferase I inhibitor caused a 
potent inhibition of both type I and III collagen expression in these cells (29), rottlerin, a potent and highly-specific inhibitor of PKC- $\delta$, also inhibited both type I and III collagen gene expression in both normal and SSc fibroblasts. Furthermore, cultured SSc fibroblasts displayed elevated levels of PKC- $\delta$, providing support to the hypothesis that PKC- $\delta$ plays a role in the pathogenesis of increased collagen gene expression in SSc (30). However, the precise role of non-Smad pathways in the pathogenesis of tissue fibrosis in SSc has not been completely elucidated.

\section{Alterations in the transcription of collagen genes.}

A crucial element in the pathogenesis of SSc is the abnormal regulation of expression of the genes involved in the production and deposition of type I collagen, the most prevalent protein in fibrotic lesions from patients with SSc and the protein responsible for the most serious clinical manifestations of the disease. Numerous studies have shown that SSc fibroblasts display an increased expression of these genes which is determined at the transcriptional level. The upregulated transcriptional activity of collagen genes in SSc appears to be autonomous and is maintained even when cells are cultured in vitro for numerous passages. It is this persistent and autonomous upregulation of expression of collagen genes which distinguishes the process of normal wound healing from the disease state in SSc. The most important elements responsible for the regulation of expression of the genes encoding type I collagen are located in the 5' promoter and first intron regions. There are numerous elements which exert enhancer or repressor functions on the overall transcriptional activity of these genes and are capable of regulating both the basal production of collagen as well as its production during pathologic conditions. Transcription factors are capable of specific binding to specific regulatory DNA sequences in the 5' promoter and in the first intron of collagen genes causing activation or 
suppression of collagen gene expression. The transcription factors involved in the regulation of collagen gene expression are quite numerous and additional ones continue being identified and described (31). Some of the most important and well-studied are listed in Table II. The CCAAT box, for example, is a regulatory region present in the promoter region of the genes encoding $\alpha 1$ and $\alpha 2$ chains of type I collagen (COL1A1 and COL1A2). Three different CCAAT binding factor proteins (CBF-A,B,C) may bind to this region and activate type I collagen transcription. Another regulatory site is the Nuclear Factor-1 binding site, located in the proximal promoter region of COL1A1 and COL1A2. Nuclear Factor-1, an intranuclear regulatory protein, binds to these regions and also causes the activation of collagen gene expression. $\mathrm{Sp} 1$ is another intranuclear transcription factor which binds to a GC-rich region in the proximal promoter at sites near those recognized by NF1 and is a potent stimulator of collagen gene expression. Elevated Sp1 and CBF binding to specific sequences in type I collagen genes has been demonstrated in SSc fibroblasts $(32,33)$. These observations indicate the crucial role that these two transcription factors play in the development of tissue fibrosis in SSc. Another important transcription factor which has been recognized and characterized recently is C-Krox (34). This protein appears to exert potent downregulation of collagen gene expression and, thus, may represent a counterbalance to $\mathrm{Sp} 1$ and $\mathrm{CBF}$. The role of C-Krox in SSc, however, has not been determined. Alterations in either the transcription factors or their binding sites may directly relate to the pathogenesis of SSc, creating a mosaic of pathogenic possibilities that can be targeted with new therapies for SSc.

\section{Endothelial cells and vascular alterations.}

Vascular dysfunction appears to be one of the earliest clinical manifestations of SSc and it has been suggested to be a crucial initiating event in SSc pathogenesis (35). Small blood 
vessels in affected tissues from SSc patients show perivascular cellular infiltration with activated $\mathrm{T}$ cells similar to that present in affected skin and internal organs. It has been postulated that cytokines or growth factors such as TGF- $\beta$ secreted by these activated lymphocytes cause activation and injury of small vessel endothelial cells inducing their expression of MHC class I and II antigens and adhesion ligand ICAM-1. As described above, TGF $\beta$ causes an upregulation of CTGF which in turn induces an increased production of ECM components as well as an upregulation of PDGF. PDGF is a potent endothelial cell mitogen which causes increased endothelial cell proliferation. It has also been shown that in SSc there is a downregulation of vascular endothelial growth factor (VEGF) which results in decreased and impaired neovascularization. Chemo-attraction of fibroblasts into the vessel wall and transdifferentiation of resident vessel wall fibroblasts into myofibroblasts occurs as a result of the effects of the locally-secreted cytokines, leading to increased collagen synthesis and deposition. Endothelial injury causes the subendothelium to be exposed to circulating platelets which eventually adhere to it and initiate fibrin deposition and intravascular thrombus formation. The vascular fibroproliferative lesions and intravascular platelet thrombosis inevitably result in a state of local hypoxia in affected tissues. Recent studies have demonstrated that local hypoxia can further cause tissue fibrosis by activation of collagen and TGF $\beta$ genes.

Vasodilation also appears to be impaired in SSc patients. Vasodilation is usually controlled by both endothelial and nonendothelial (neurological) mechanisms. Endothelial cells regulate vascular tone by secreting vasoactive substances such as nitric oxide and calcitoninrelated peptide which are vasodilatory as well as endothelin-I which is a potent vasoconstrictor in patients with SSc. It appears that in SSc there is a relative deficiency of vasodilator molecules and a relative increase of vasoconstrictor ones which in turn causes further vascular hypoxia and 
endothelial injury resulting in the production and release of additional cytokines from the activated inflammatory cells, thus maintaining the vicious cycle of endothelial injury and fibrosis. Indeed, several studies have demonstrated increased levels of endothelin and of its receptors in affected SSc microvasculature as well as in parenchyma of affected tissues (36). The effects of vascular dysfunction in patients with SSc are most dramatic when they involve the pulmonary and renal arterioles, causing endothelial injury with subsequent intravascular thrombus formation as well as fibrous tissue deposition in the myointimal region of the vessels. The constellation of these multiple vascular alterations leads to renal crisis and pulmonary hypertension, respectively, which are the most prevalent causes of morbidity and mortality in patients with SSc.

\section{Conclusion.}

Although a unified hypothesis encompassing all the components of SSc pathogenesis is sought, owing to the heterogeneity of the disease, the answer may lie not in a single pathway but in a constellation of different pathogenic mechanisms. A causative agent such as a virus of chemical substance may initiate tissue inflammation in a patient with a genetic predisposition for SSc. On the other hand, the initial event may be the engraftment of microchimeric cells after materno-fetal cell transfer with a subsequent graft-versus-host event. The pathogenesis of SSc as described above may follow a different path in individual patients although each of these pathways would lead to the same end results of altered humoral and cellular immunity, vascular endothelial lesions and, most importantly, excessive collagen deposition in skin and internal organs. Thus, a better understanding of the pathogenesis of SSc and the formulation of valid and testable hypotheses will undoubtedly provide the foundations to render reachable the goal of developing novel and effective therapeutic agents for this incurable disease. 


\section{Acknowledgements}

Supported by NIH grant AR19616. Dr. Derk was supported by NIH training grant AR07583. The expert assistance of Kate Salmon is greatly appreciated. 
Table I. Principal autoantibodies in Systemic Sclerosis.

\begin{tabular}{|c|c|c|}
\hline Autoantibody & Target Antigen & Clinical Association \\
\hline anti-Scl-70 & DNA topoisomerase I & Diffuse SSc \\
\hline \multirow{4}{*}{ anti-centromere } & Kinetochore proteins & Limited SSc \\
\hline & CENP A $(17 \mathrm{kDa})$ & \\
\hline & CENP B $(80 \mathrm{kDa})$ & \\
\hline & CENP C (140 kDa) & \\
\hline anti-RNA polymerase I & Complex of 210-14 kDA proteins & $\begin{array}{c}\text { Progressive SSc, } \\
\text { organ involvement }\end{array}$ \\
\hline anti-fibrillarin & $\begin{array}{l}\text { Nucleolar protein of } 34 \mathrm{kDa} \\
\text { Component of U3-RNP }\end{array}$ & Diffuse SSc \\
\hline anti-PM-Scl & $\begin{array}{c}\text { Complex of 110-20 kDA } \\
\text { Nucleolar and nuclear proteins }\end{array}$ & Polymyositis/SSc overlap \\
\hline anti-nRNP & Nuclear ribonucleoprotein & $\begin{array}{l}\text { Mixed connective } \\
\text { tissue disease }\end{array}$ \\
\hline anti-7-2-RNP & $\begin{array}{c}\text { Nucleolar protein of } 40 \mathrm{kDa} \\
\text { Complexed with } 7-2 \text { and } 8-2 \mathrm{RNAs}\end{array}$ & Limited SSc \\
\hline anti-NOR-90 & $\begin{array}{c}\text { Protein of } 90 \mathrm{kDa} \text { localized to the } \\
\text { nucleolar organizer region }\end{array}$ & Lung involvement \\
\hline anti-mitochondrial & $\begin{array}{c}\text { M2 complex of } 70 \mathrm{kDA} \text { and } \\
47 \mathrm{kDa} \text { proteins }\end{array}$ & $\begin{array}{c}\text { Limited SSc associated } \\
\text { with PBC } \\
\end{array}$ \\
\hline Anti-Ku & $\begin{array}{l}\text { Nucleolar heterodimer of } 70 \mathrm{kDa} \text { and } \\
80 \mathrm{kDa} \text { polypeptide chains }\end{array}$ & Polymyositis/SSc overlap \\
\hline Anti-Th/To & $\begin{array}{c}\text { RNAse MRP and RNAse } \\
\text { P ribonucleoprotein complexes }\end{array}$ & \\
\hline
\end{tabular}

$\mathrm{CENP}=$ centromere protein; $\mathrm{PM}=$ polymyositis; $\mathrm{RNP}=$ ribonuclear protein; $\mathrm{NOR}=$ nucleolar organizing region. 
Table II. Selected transcription factors involved in the regulation of type I collagen gene expression.

\begin{tabular}{|c|c|c|c|}
\hline $\begin{array}{c}\text { Transcription } \\
\text { Factor }\end{array}$ & Target Genes & $\begin{array}{c}\text { Promoter } \\
\text { Binding Site }\end{array}$ & $\begin{array}{c}\text { Effect on Type I } \\
\text { Collagen Gene } \\
\text { Expression }\end{array}$ \\
\hline $\begin{array}{l}\boldsymbol{C B F} \\
\text { (CCAAT binding factor) } \\
\text { CBF-A } \\
\text { CBF-B } \\
\text { CBF-C }\end{array}$ & $\begin{array}{l}\text { COL1A1 } \\
\text { COL1A2 }\end{array}$ & -100 to -96 bp & Activation \\
\hline $\begin{array}{l}\text { NF-1 } \\
\text { (nuclear factor-1) }\end{array}$ & COL1A2 & -350 to $-300 \mathrm{bp}$ & Activation \\
\hline $\begin{array}{l}S p-1 \\
\text { (Zinc finger family) }\end{array}$ & $\begin{array}{l}\text { COL1A2 } \\
\text { COL1A1 }\end{array}$ & $\begin{array}{l}-303 \text { to }-279 b p \\
-164 \text { to }-159 b p \\
-128 \text { to }-123 b p \\
-129 \text { to }-107 b p\end{array}$ & Activation \\
\hline IF1/IF2 & $\begin{array}{l}\text { COL1A1 } \\
\text { COL1A2 }\end{array}$ & $\begin{array}{l}-190 \text { to }-170 b p \\
-160 \text { to }-130 b p \\
-133 \text { to }-71 b p \\
-165 \text { to }-155 b p\end{array}$ & Inhibition \\
\hline $\begin{array}{l}\boldsymbol{c - K r o x} \\
\text { (Zinc finger family) }\end{array}$ & COL1A1 & -195 to -168 bp & Inhibition \\
\hline $\begin{array}{l}\text { JunD } \\
\text { c-Jun } \\
\text { c-fos }\end{array}$ & COL1A1 & $\begin{array}{l}+292 \text { to }+670 \mathrm{bp} \\
\quad \text { (first intron) }\end{array}$ & Inhibition \\
\hline
\end{tabular}




\section{References:}

1. Maul GG, Jimenez SA, Riggs E, Zeimnicka-Kotula D. Determination of an epitope of the diffuse scleroderma marker antigen topoisomerase I. Sequence similarity with retroviral p30 ${ }^{\text {gag }}$ protein suggests a possible cause for autoimmunity in scleroderma. Proc Nat Acad Sci USA 1989;86:8492-8496.

2. Dang H, Dauphinee MJ, Talal N, Garry RF, Seibold JR, Medsger TA, Alexander S, Feghali CA. Serum antibody to retroviral gag proteins in systemic sclerosis. Arthritis Rheum 1991; 35(9): 1336-7.

3. Lunardi C, Bason C, Navone R, Millo E, Damonte G, Corrocher R, Puccetti A. Systemic sclerosis immunoglobulin $\mathrm{G}$ autoantibodies bind the human cytomegalovirus late protein UL94 and induce apoptosis in human endothelial cells. Nat Med 2000; 6(10): 1183-6.

4. Newrkirk MM, van Venrooij WJ, Marshall GS. Autoimmune response to U1 small nuclear ribonucleoprotein (U1 snRNP) associated with cytomegalovirus infection. Arthritis Res 2001; 3(4): 253-8.

5. Johnson RW, Tew MB, Arnett FC. The genetics of systemic sclerosis. Curr Rheumatol Rep 2002; 4:99-107.

6. Arnett FC, Howard RF, Tan FK, Moulds JM, Bias WB, Durban E. Increased prevalence of systemic sclerosis in a Native American tribe in Oklahoma: association with an Amerindian HLA haplotype. Arthritis Rheum 1996; 39: 1362-70.

7. Hata R, Akai J, Kimura A, Ishikawa O, Kuwana M, Shinkai H et al. Association of functional microsattelites in the human type I collagen $\alpha 2$ chain (COL1A2) gene with systemic sclerosis. Biochem Biophys Res Com 2000; 272:36-40.

8. Crilly A, Hamilton J, Clark CJ, Jardine A, Madlock A. Analysis of transforming growth factor $\beta$, gene polymorphisms in patients with systemic sclerosis. Ann Rheum Dis 2002; 61:678-81.

9. Tan FK, Wary N, Kuwana M, Chakrabotry R, Bona CA, Milewicz DM et al. Association of fibrillin 1 single-nucleopeptide polymorphism haplotypes with systemic sclerosis in Choctaw and Japanes populations. Arthritis Rheum 2001;44:893-901.

10. Maloney S, Smith A, Furst DE, Myerson D, Rupert K, Evans PC et al. Microchimerism of maternal origin persists into adult life. J Clin Invest 1999; 104:41-47.

11. Artlett CM, Smith JB, Jimenez SA. Identification of fetal DNA and cells in skin lesions from women with systemic sclerosis. N Engl J Med 1998;1186-91. 
12. Ohtsuka T, Miyamoto Y, Yamakage A, Yamazaki S. Quantitative analysis of microchimerism in systemic sclerosis skin tissue. Arch Dermatol Res 2001; 293: 387-91.

13. Artlett CM, Cox LA, Ramos RC, Dennis TN, Fortunato RA, Hummers L, Jimenez SA, Smith JB. Increased microchimeric CD4+ lymophytes in peripheral blood from women with systemic sclerosis. Clin Immunol 2002;103:303-308.

14. Douvas AS, Achten M, Tan EM. Identification of a nuclear protein (Scl-70) as a unique target of human antinuclear antibodies in scleroderma. J Biol Chem 1979; 254(20): 1051422 .

15. Maul GG, French BT, van Venrooij WJ, Jimenez SA. Topoisomerase I identified by scleroderma 70 antisera: enrichment of topoisomerase I at the centromere in mouse mitotic cells before anaphase. Proc Natl Acad Sci USA 1986;83(14):5145-9.

16. Kraling BM, Maul GG, Jimenez SA. Mononuclear cellular infiltrates in clinically involved skin from patients with systemic sclerosis of recent onset predominantly consists of monocytes/macrophages. Pathobiol 1995;63:48-56.

17. Yurovsky VV, Wigley FM, Wise RA, White B. Skewing of the CD8+ T-cell repertoire in the lungs of patients with systemic sclerosis. Hum Immunol 1996;48(1-2): 84-97.

18. Sakkas LI, Xu B, Artlett CM, Lu S, Jimenez SA, Platsoucas CD. Oligoclonal T cell expansion in the skin of patients with systemic sclerosis. J Immunol 2002; 168(7): 3649-59.

19. Ferrarini M, Steen V, Medsger TA, Whiteside TL. Functional and phenotypic analysis of T lymphocytes cloned from the skin of patients with Systemic Sclerosis. Clin Exp Immunol 1990;79(3): 346-52.

20. Postlethwaite AE. Connective tissue metabolism including cytokines in scleroderma. Curr Opin Rheumatol 1995;7:535-40.

21. Smith EA, LeRoy EC. A possible role for transforming growth factor- $\beta$ in systemic sclerosis. J Invest Dermatol 1990;95(6 Suppl):125S-127S.

22. Branton MH, Kopp JB. TGF- $\beta$ and fibrosis. Microbes Infect 1999;1:1349-1365.

23. Clark DA, Coker R. Transforming growth factor-beta (TGF- $\beta$ ). Int J Biochem Cell Biol 1998; 30:293-298.

24. Massague J. How cells read TGF- $\beta$ signals. Nat Rev Mol Cell Biol 2000;1:169-78.

25. Wrana JL, Attisano L. The Smad pathway. Cytokine Growth Factor Rev 2000;11:5-13.

26. Varga J. Scleroderma and Smads:dysfunctional Smad family dynamics culminating in fibrosis. Arthritis Rheum 2002; 46: 1703-13. 
27. Dong C, Zhu S, Wang T, Yoon W, Li Z, Alvarez RJ, ten Dijke P, White B, Wigley FM, Goldschmidt-Clermont PJ. Deficient Smad 7 expression: a putative molecular defect in scleroderma. Proc Natl Acad Sci USA 2002;99:3908-3913.

28. Leask A, Holmes A, Abraham DJ. Connective tissue growth factor: a new and important player in the pathogenesis of fibrosis. Curr Rheum Rep 2002;4:136-142.

29. Rosenbloom J, Saitta B, Gaidarova S, Sandorfi N, Rosenbloom JC, Abrams WR, Hamilton AD, Sebti SM, Kucich U, Jimenez SA. Inhibition of type I collagen gene expression in normal and systemic sclerosis fibroblasts by a specific inhibitor of geranylgeranyl transferase I. Arthritis Rheum 2000; 43(7): 1624-1632.

30. Jimenez SA, Gaidarova S, Saitta B, Sandorfi N, herrich DJ, Rosenbloom JC et al. Role of protein kinase $\mathrm{C}-\delta$ in the regulation of collagen gene expression in scleroderma fibroblasts. J Clin Invest 2001;108:1395-1403.

31. Ghosh AK. Factors involved in the regulation of type I collagen gene expression: implication in fibrosis. Exp Biol Med 2002;227(5):301-314.

32. Hitraya EG, Varga J, Artlett CM, Jimenez SA. Identification of elements in the promoter of the $\alpha 1$ (1) procollagen gene involved in its upregulated expression in systemic sclerosis. Arthritis Rheum 1998;41:2048-2058.

33. Saitta B, Gaidarova S, Cicchillitti L, Jimenez SA. CCAAT binding transcription factor binds and regulates human COL1A1 promoter activity in human dermal fibroblasts: demonstration of increased binding in systemic sclerosis fibroblasts. Arthritis Rheum 2000; 43(10): 2219-2229.

34. Widom RL, Culic I, Lee JY, Korn JH. Cloning and characterization of hcKrox, a transcriptional regulator of extracellular matrix gene expression. Gene 1997; 198(1-2): 407420.

35. LeRoy EC. Systemic sclerosis. A vascular perspective. Rheum Dis Clin North Am 1996;22:695-708.

36. Abraham DJ, Vancheeswaran R, Dashwood MR, Rajkumar VS, Pantelides P, Xu SW, du Bois RM, Black CM. Increased levels of endothelin-1 and differential endothelin type A and $\mathrm{B}$ receptor expression in scleroderma-associated fibrotic lung disease. Am J Pathol 1997;151:831-41. 


\section{LEGENDS}

Figure 1: Diagrammatic representation of the TGF- $\beta / \mathrm{Smad}$ cascade of collagen gene activation.

Key for Figure: $\mathrm{SSc}=$ systemic sclerosis; TGF- $\beta=$ transforming growth factor- $\beta$; $\mathrm{PDFG}=$ platelet derived growth factor; $\mathrm{CTGF}=$ connective tissue growth factor; $\mathrm{P}=$ phosphorylation; $\mathrm{T} \beta \mathrm{RII}=$ transforming growth factor $\beta$ receptor 2 ; T $\beta \mathrm{RI}=$ transforming growth factor $\beta$ receptor 1 . 